\title{
O ENSINO SUPERIOR EM FACE DAS MUTACC̃̃ES NO MUNDO DO TRABALHO: UM DEBATE NECESSÁRIO
}

\author{
Fabrício Aparecido Bueno ${ }^{\mathrm{I}}$ \\ Sérgio Dias Cirino II \\ I Universidade Federal de Minas Gerais (UFMG), Belo Horizonte (MG), Brasil; fabricioapbueno@hotmail.com \\ II Universidade Federal de Minas Gerais (UFMG), Belo Horizonte (MG), Brasil; sergiocirino99@yahoo.com
}

Moraes, R. C. (2019). Ensino superior e formação para o trabalho: Reflexões sobre a experiência norte-americana. Unesp. 143p.

No mundo todo, tem se apresentado como uma tarefa cada vez mais premente na agenda de governantes e pesquisadores de diferentes áreas pautar a discussão sobre os rumos das políticas de formação profissional em face das novas configurações assumidas pelo mundo do trabalho (Takayanagui, 2012). Nesse cenário, ganham proeminência os debates em torno da relevância social da educação de nível superior, particularmente no que diz respeito a como ela deve se organizar para atender aos novos ditames econômicos e laborais de uma sociedade em rápido ritmo de transformação.

O livro Ensino superior e formação para o trabalho: reflexóes sobre a experiência norte-americana, de autoria do cientista e filósofo político Reginaldo Corrêa de Moraes, presta uma salutar contribuição a esse campo de discussões, ao trazer análises bastante oportunas sobre como esse debate vem sendo travado no contexto norte-americano. A pertinência da obra mostra-se, em especial, pela capacidade do autor de conseguir oferecer uma valiosa descrição sobre dilemas presentes no campo de interface entre ensino superior e formação para o trabalho nos Estados Unidos (EUA), um país cujo sistema educacional por vezes aparece enaltecido, no âmbito das recomendações de organismos multilaterais (como Banco Mundial, Comissão Econômica para América Latina e Caribe, Fundo Monetário Internacional, dentre outros), como modelo a ser seguido no que tange ao modo como a educação superior deve se adaptar às exigências de uma economia globalizada e às características de um mundo do trabalho em mutação (Sguissardi, 2009).

Essa discussão se mostra de particular importância no âmbito da conjuntura brasileira atual, dado o desencadeamento de processos que intensificam a reconfiguração da estrutura sociolaboral do país, notadamente a partir das modificações trazidas pelas recentes reformas na legislação trabalhista. $\mathrm{Na}$ apresentação da obra, o próprio autor deixa indicada essa pretensão de contribuição do seu trabalho ao advertir: "nem sempre estamos falando apenas de problemas 'deles'. E, talvez, falar dos males dos outros nos induza a olhar com menos indulgência os nossos próprios desafios e improbidades" (Moraes, 2019, p. 12).

O livro nasce como resultado de um estudo desenvolvido entre 2016 e 2018 com o intuito de analisar programas de desenvolvimento da força de trabalho (workforce development) envolvendo os community colleges (CCs), escolas que, no sistema educacional norte-americano, situam-se na fronteira entre o ensino médio e o superior. A esse respeito, cabe salientar que, nos oito anos que precederam a publicação dessa obra, Moraes dedicou-se ao desenvolvimento de um amplo programa de pesquisa a respeito da educação superior nos EUA, tendo sido a análise dos CCs a via de entrada pela qual 
escolheu ingressar nesse complexo campo de investigação. Aliás, vale lembrar que, em 2014, a revista Cadernos de Pesquisa teve a oportunidade de publicar um artigo de autoria de Moraes a respeito da experiência norte-americana dos CCs, trabalho no qual o autor defende como argumento central a tese de que a vultuosa expansão da rede dessas instituições nos EUA deveria ser encarada como expressão do acirramento de problemáticas sociais e políticas bastante candentes naquele país (Moraes, 2014). Nesse mesmo texto, Moraes procura também chamar a atenção para uma recente expansão dos departamentos de workforce development, de forte viés vocacionalista, no âmbito dos CCs.

Parte das contribuiçóes resultantes dos primeiros anos dessa ampla pesquisa conduzida pelo autor é condensada na obra Educação superior nos Estados Unidos. Nesse trabalho, Moraes (2015) mais uma vez destaca o surpreendente crescimento da preocupação com a criação de unidades especiais voltadas para o ensino vocacional no corpo dos CCs, fenômeno que o autor adotaria como ênfase principal de suas investigações a partir de 2016. A obra aqui resenhada constituiu-se como um dos produtos resultantes dessa segunda etapa de investigação. Nela, Moraes dedica-se a analisar com maior profundidade os fatores associados ao crescimento da propagação de uma literatura fortemente vocacionalista no campo de debates sobre o ensino superior norte-americano, com vistas a lançar luz sobre aspectos que ajudam a compreender o fortalecimento da tendência de se apostar cada vez mais nos CCs como instituições direcionadas para a preparação de uma mão de obra condizente com as demandas do mercado de trabalho.

A obra está estruturada em quatro partes. A primeira é composta por capítulos dedicados a discutir as propostas de adequação dos programas vocacionais norte-americanos às novas exigências do mundo do trabalho. Inicialmente, o autor procura analisar detalhadamente um conjunto de relatórios, produzidos desde o início dos anos 1980, que defendem a necessidade de reformas na educação norte-americana com vistas a aperfeiçoar a sua capacidade de responder aos novos desafios econômicos e laborais. Moraes associa a recorrência com que esses relatórios passam a ser produzidos nos EUA a uma crença alimentada por análises da década de 1970, segundo as quais o dinamismo da economia norte-americana entraria inevitavelmente em uma trajetória de queda nos anos seguintes. Caberia à educação o desafio de sustentar projetos de prosperidade para a nação, mediante a preparação de uma mão de obra com novas competências para enfrentar o contexto de competição econômica global.

Como complemento à análise dos relatórios, que sustentam a necessidade de reformas educacionais, o autor empenha-se também em apresentar um conjunto de estudos acadêmicos, produzidos por pesquisadores norte-americanos ao largo dos últimos 30 anos, dedicados a abordar a relação entre educação e desenvolvimento da força de trabalho. Trata-se de artigos acadêmicos, produzidos por especialistas de diferentes áreas (economia, pedagogia, sociologia, psicologia e ciência política), todos, em alguma medida, interessados em registrar as mudanças econômicas, sociais, demográficas e tecnológicas pelas quais vem passando o mundo globalizado, além dos impactos dessas transformações para a organização tanto do trabalho e das ocupações quanto, sobretudo, do ensino para atender às exigências de formação de novas competências para atuar nesse emergente cenário.

Ao final da primeira parte da obra, Moraes propõe-se a fazer uma análise mais específica de aspectos das transformações no mundo do trabalho, especialmente em relação à nova Divisão Internacional do Trabalho (DIT). O autor evidencia que há uma forte tendência na literatura especializada sobre essa temática de tomar como inevitáveis os processos de pulverização das carreiras e dos ofícios provocados pela escalada de fenômenos tais como a terceirização, a automação e a internacionalização do trabalho. Nos dois capítulos finais dessa primeira parte, o autor concentra-se em oferecer um rápido panorama das principais tendências apontadas pelos especialistas no que tange às novas condições de trabalho, geradas pela intensificação de processos como a terceirização e mundialização das tarefas, com ênfase em questionamentos a respeito de como, afinal, todas essas transformações impactam na preparação de futuros trabalhadores para atuar no contexto de uma nova conjuntura de relações produtivas e trabalhistas.

A segunda parte do livro é dedicada a explorar o ganho de prestígio, em solo norte-americano, do modelo pedagógico do apprenticeship, inspirado na experiência educacional alemã. No primeiro 
capítulo da segunda parte, Moraes busca situar alguns dos trabalhos mais expoentes que, nas duas últimas décadas do século XX, defenderam introduzir a apprenticeship na educação norte-americana (em níveis médio, superior e vocacional).

A seleção da literatura realizada por Moraes para descrever os principais argumentos levantados pelos entusiastas da apprenticeship denota o reducionismo das concepções educacionais que costumam estar presentes nesses discursos. Na maior parte do tempo, como mostra o autor, prevalece uma perspectiva que restringe o papel da educação a uma preparação complacente e pragmática para o mercado de trabalho. Isso se torna particularmente claro na análise que o autor faz do livro Apprenticeship for adulthood, de Stephen F. Hamilton, publicado em 1990. O que Moraes procura evidenciar com essa análise é o quanto o interesse pelo aproveitamento do que se pressupunha haver de vantajoso no modelo alemão ancorava-se, exclusivamente, em uma preocupação utilitarista e funcional com relação aos benefícios que a importação de aspectos desse modelo poderia oferecer aos norteamericanos do ponto de vista da preparação de uma mão de obra mais adaptada aos novos ditames do mercado financeiro. Ademais, fica claro o quanto discrepâncias sociais, culturais e estruturais entre as duas nações eram pouco ou nada questionadas no âmbito dessa literatura, tampouco se percebia qualquer preocupação em pensar a educação para além de uma função estritamente tecnicista e instrumental.

A terceira parte da obra cumpre o papel de esclarecer que a discussão hegemônica sobre o desenvolvimento da força de trabalho no contexto norte-americano não se reduz à defesa de reformas do sistema educacional com vistas a torná-lo mais adequado aos novos ditames da economia. Uma vasta literatura concentra-se em alertar para a insuficiência de se apostar somente na educação formal como meio para garantir o desenvolvimento das competências e habilidades requeridas pelo novo cenário das ocupações profissionais, indicando a necessidade de se pensar no desenvolvimento de "predisposições essenciais para o sucesso" a partir de uma melhor gestão da vida das famílias. Muito apropriadamente, Moraes consegue evidenciar que tanto os argumentos em favor de reformas do ensino norte-americano quanto a literatura dedicada a enaltecer o papel da família no desenvolvimento de predisposiçóes essenciais para o sucesso são igualmente desprovidos de qualquer consideração crítica em relação aos valores e preceitos subjacentes a essa nova conjuntura social e econômica, que estaria a exigir um trabalhador de novo tipo. Além do mais, compõem-se de discursos fortemente ancorados em concepções preconceituosas a respeito da realidade, das condições e dos hábitos das famílias economicamente menos favorecidas.

A quarta e última parte do livro é composta por capítulos que, em conjunto, proporcionam uma visão panorâmica dos aspectos mais relevantes e centrais do debate em torno da educação superior norte-americana ao largo das últimas três décadas. O primeiro dos sete capítulos que compõem essa parte aborda, especificamente, a problemática da massificação do ensino superior norte-americano - cujo início data dos anos imediatamente posteriores à Segunda Guerra Mundial, antecipando em algumas décadas o que somente no final do século XX viria a ocorrer na maioria dos outros países - e os impasses acarretados por esse processo na discussão sobre a problemática do "sucesso".

No capítulo seguinte, Moraes interroga desigualdade do acesso e das condições de "sucesso" no âmbito do próprio sistema educacional. A partir do confronto entre os modelos educacionais alemão e norte-americano, o autor procura mostrar que a principal diferença entre eles, no que diz respeito ao modo como enfrentam a questão da desigualdade, não está precisamente em um maior ou menor potencial de inclusão ou exclusão inerente a cada modelo, mas sim nas formas como se busca gerenciar, em cada caso, essas desigualdades. A propósito, uma análise mais detida sobre os reflexos da desigualdade social nas discussões relativas à formação profissional nos EUA é matéria constituinte de outros dois capítulos dessa parte, no âmbito dos quais Moraes busca problematizar uma temática fortemente presente no discurso público norte-americano: a noção de educação como panaceia, sarcasticamente alcunhada, por alguns analistas, de "evangelho pedagógico".

O autor procura frisar que essa perspectiva caminha de mãos dadas com a valorização que os CCs vêm angariando ao longo dos últimos anos no âmbito dos debates em torno da educação superior 
estadunidense, ainda que não se constituam, no sentido mais estrito do termo, como instituições originariamente de ensino superior. Tomando como mote a ideia de educação como esteio de formação da força de trabalho, os CCs, vistos como instituições mais flexíveis e capilarizadas, angariam a missão de responder às demandas da nova estrutura ocupacional engendrada pela "modernização" da economia (automação, deslocalização de plantas, reengenharia, downsizing, etc.).

O capítulo final da obra deixa como mensagem a importância de se ter sempre em consideração a íntima vinculação entre as configurações de um sistema de ensino superior e as problemáticas inerentes aos arranjos sociais que definem o modo como um país procura estruturar sua economia e suas relações de trabalho. É preciso mais uma vez insistir na relevância dessa discussão em um momento no qual, no mundo todo, e também no Brasil, assiste-se a um acirramento das discussões em torno da necessidade de reforma dos sistemas de ensino superior com vistas à formação de um profissional mais preparado para enfrentar o mercado de trabalho.

A obra que aqui apresentamos como essencial para compor essas discussões cumpre uma precípua função de alertar para os riscos inerentes a uma adesão cega aos ditames da economia ao se debaterem os rumos da educação superior para o futuro. Não se trata de negar a função econômica da educação superior, tampouco defender uma ruptura entre instituições formadoras e demandas do setor produtivo, mas sim advertir para o quanto o debate educacional tende a se empobrecer no momento em que preceitos econômicos passam a se constituir como os principais, quando não os únicos, norteadores das discussões.

Por fim, asseguramos que a leitura do livro poderá contribuir para as reflexões daqueles interessados em compreender as especificidades dos desafios inerentes ao sistema de ensino superior norte-americano, bem como proporcionar valiosas referências para que possamos pensar as particularidades dos desafios enfrentados no contexto do nosso próprio sistema de ensino superior.

Boa leitura!

\section{Referências}

Moraes, R. C. (2014). Ensino superior de curta duração: a experiência norte-americana dos community colleges. Cadernos de Pesquisa, 44(152), 450-464.

Moraes, R. C. (2015). Educação superior nos Estados Unidos. Unesp.

Moraes, R. C. (2019). Ensino superior eformação para o trabalho: Reflexões sobre a experiência norte-americana. Unesp. Sguissardi, V. (2009). Universidade brasileira no século XXI: Desafios do presente. Cortez.

Takayanagui, A. D. (2012). La nueva agenda de transformación de la educación superior en América Latina. Perfiles Educativos, 34(138), 329-352.

\section{Nota sobre autoria}

A resenha derivou de um processo de elaboração colaborativa entre os dois autores.

\section{Como citar esta resenha}

Bueno, F. A., \& Cirino, S. D. (2021). O ensino superior em face das mutações no mundo do trabalho: Um debate necessário. [Resenha do livro Ensino superior e formação para o trabalho: Reflexões sobre a experiência norte-americana, de Moraes, R. C.]. Cadernos de Pesquisa, 51, e07736. https://doi.org/10.1590/198053147736 